\title{
Impact of Distributed Generation Integration on Distribution System Reliability
}

\author{
Galiveeti Hemakumar Reddy ${ }^{1,2 *}$, Arup Kumar Goswami ${ }^{2}$ and Nalin B. Dev Choudhury ${ }^{2}$ \\ 'Department of Electrical and Electronics Engineering, Institute of Aeronautical Engineering, Hyderabad - 500043, \\ Telangana, India; ghkr220@gmail.com \\ 2Department of Electrical Engineering, National Institute of Technology Silchar - 788010, Assam, India; \\ gosarup@gmail.com,nalinbdc@yahoo.com
}

\begin{abstract}
Objectives: To study the impact of Distributed Generation (DG) integration and automation on distribution system (DS) reliability. Impact of switch operational failures is to be studied. Methods/Statistical Analysis: The system reliability is estimated using time sequential Monte Carlo Simulation (MCS) considering time varying load models. The uncertainties of wind and solar powers are modelled by using Weibull and Beta probability distribution functions respectively. The concept of expectation is used for fuse and switch operational failures to determine the average outage time. System equipment is modelled using two state continues Markov modelling. Findings: The impact of DGs and system automation on distribution system reliability is estimated. The impact analysis is done on a practical Indian distribution system. The impact on system reliability due to operational failures of the fuses and switches is analysed. The failures of substation equipment and DGs are also included for reliability evaluation. The load transfer restrictions are applied on feeders and load transfer capacity is evaluated based on the instantaneous loading of the feeder. Both system reliability and load point reliability is evaluated for impact analysis and results are compared. Application/Improvements: The results contribute the generic observations regarding the impact of DG integration and operational failures of switches.
\end{abstract}

Keywords: Distribution Automation, Distributed Generation, Monte Carlo Simulation, Probability Distributions, Solar Power, Wind Power

\section{Introduction}

Reliability of the system primarily relates to equipment outages and customer interruption. Automation of the distribution system and substation greatly reduces the time required for fault detection, fault location and isolation in an electrical distribution system. Different Load Point (LP) and DS oriented reliability indices were used to evaluate the DS reliability. The basic LP indices are average failure rate, average unavailability, annual unavailability and system indices System Average Interruption Frequency Index (SAIFI), System Average Interruption Duration Index (SAIDI), Customer Average Interruption
Duration Index (CAIDI), and Expected Energy Not Supplied (EENS). The loads in the DS are having a probabilistic nature. The system loading can be changed with time, but the everyday loading of the system approximately follows the same pattern and varies seasonally. The reliability evaluation cannot be accurate for constant or average loads. Time varying load models were discussed for DS reliability evaluation 1 . DG integration has been used for reliability and efficiency improvement of DS.

The concept of segments was used for DG placement and optimal locations were determined for time varying load pattern . Time varying load models were used for DG integration to the DS 3 . Wind and solar output

${ }^{*}$ Author for correspondence 
powers depend on the weather conditions; meanwhile weather conditions are continuously varying with time. The output power varies with time according to availability of wind speed and solar radiance. The time varying wind power generation were discussed for placement of wind generators in medium voltage DS4. Probabilistic PV output models were discussed for power flow studies of transmission system ${ }^{5}$. Beta probability distribution functions were used to model the probabilistic nature of PV output $t^{6,7}$.

The basic DS and LP reliability indices were discussed and the mathematical evaluation procedure was explained for different configurations of the DS ${ }^{8}$. MCS methods were explained for reliability evaluation of DS². Component modelling was given for assessment of reliability studies. MCS method was used for determination of reliability indices of a teachingDS ${ }^{10}$ and the results were compared with analytical methods. MCS approach to evaluate the substation reliability wasdiscussed ${ }^{11}$. Non-sequential MCS approach was used 12 for DS reliability and loads were modelled using Markov modelling. MCS method was used to determine the reliability of different bus bar layouts ${ }^{\underline{13}}$. Reliability of active distribution networks were determined using non-sequential MCS method ${ }^{14}$. The probabilistic methods were used to evaluate the reliability of DS. The reliability indices of the DS were considered as random variables. The reliability indices were measured as probability distributions rather than average values ${ }^{15}$. The reliability of complex DS was determined by considering restoration sequence along with Network Constraints $(\mathrm{NCs})^{16}$. Parent-visit technique and breadth-first-search were used to find the affected area and division of affected area into sub groups respectively. The reconfiguration of DS was validated by examining the NCs by performing the branch-oriented load flow. The DS reliability was evaluated by considering the switching sequence and variable restoration times ${ }^{17}$. A fault traversal method was used to determine the affected areas. The reconfiguration and restoration were done based on the customer reliability demand and available energy sources.

Optimal interconnection planning of micro grids with DGs was discussed for enhancement of reliability and economic operation ${ }^{\frac{18}{}}$. The reliability benefits of DG integration were studied under the load transfer restrictions ${ }^{19}$. The combined impact of DGs and PEVs integration on distribution system reliability is evaluated for a practical Indian distribution system ${ }^{20}$. Reliability was evaluated by considering three levels of load transfer capacity associated with each of the three load levels. Variable DG (wind, solar) outputs were considered in this study. The variable DG power and loads were used for DS reliability evaluation ${ }^{21}$. The impact of system automation on reliability was discussed under the storm conditions ${ }^{22}$. In ${ }^{16}$ load flow analysis was used to examine the network constraints, which increases the computational time and memory to run load flow for each estimated configuration. It also increases the restoration time. $\mathrm{In}^{\frac{17}{7}}$, the network restoration time was determined by considering the switching times of all devices, that are operated during the restoration process and average repair times are used for all components.

Load levels were represented only one-day loading of the system instead of entire simulation year ${ }^{2}$. The outputs of DGs were fixed at particular timings. Also, while calculating reliability, the substation was considered as a single component.

The novelty of proposed works is summarized as follows.

1. The work reported in $\frac{16}{}$ uses load flow analysis to determine the NCs while determining load transfer capacity. Fixed load transfer capacity is used ${ }^{19}$. The proposed work uses the maximum loading capacity of feeders; load transfer capacity of feeder depends on the instantaneous loading of feeder.

2. The work in 2 , the time varying loads represents daily loading of the system. Proposed work considered monthly and hourly load factors for time varying loads. It will represent one year loading of the system.

3. $\mathrm{In}^{2}$ considered fixed DG outputs. While in ${ }^{19}$ used few fixed DG output levels. In proposed work, Weibull distribution function and Beta distribution functions are applied to estimates the wind and solar output powers respectively. This will give the variable DG outputs at specified time.

4. All components of the DS consisting of power transformers, distribution transformers, overhead lines, CBs, BB and DG failures are included in the reliability evaluation.

5. The impact of operational failures of fuses and switches are considered for evaluation.

6. The time sequential MCS is used for reliability evaluation. This methodology is tested on practical Indian distribution system. 
The structure of the paper as follows: section 2 explains the reliability evaluation which includes general description of the MCS method, component modelling, DG modelling, load modelling and LP and system reliability indices. The test DS description and reliability data are mentioned in section 3. Section 4 illustrates proposed reliability evaluation algorithm and assumptions for evaluation. Results and relevant discussion are analysed in section 5. Finally, section 6 concludes the work.

\section{Reliability Evaluations}

\subsection{Monte Carlo Simulation}

The MCS is the well suitable approach to determine the realistic behaviour of the real systems, in which the process is having random nature which includes failures, Time To Failure (TTF), time for restoration etc. The randomness of the system behaviour is generalized by using any of the probability distribution (exponential, normal, Beta, Weibull etc.). The time sequential MCS examines the system behaviour with time basis. The time sequential MCS is useful to determine the system reliability parameters with a specified period of time.

The time sequential MCS generates the chronological behaviour of the system by considering the stochastic nature of system states. The system states are estimated based on the stochastic modelling of their components. The DS reliability is estimated by considering the time varying loads along with the time sequential MCS on the same time base. Calculation of system reliability by taking the NY simulation years is as follows.

$$
\tilde{E}[F]=\frac{1}{N Y} \sum_{k=1}^{N Y} \mathrm{~F}\left(y_{k}\right)
$$

where

$N Y=$ simulation years

$\mathrm{F}\left(y_{k}\right)=$ Function definition of reliability indices

$y_{k}=$ Number of system states in year $k$

$k=$ Year index

\subsection{Component Modelling}

The advantage of time sequential simulation is generation of artificial operating and restoration times of respective components based on their reliability parameters. The components are represented as two state Markov models. The DS components include transformers, feeder sec- tions, lateral sections, sectionalizing devices, fuses and Normally Open (NO) switches used for load transferring. Distribution substation includes transformers, Circuit Breakers (CB) and Bus Bars (BB). Two state Markov models are used for representing the line, transformer, $\mathrm{CB}$ and $\mathrm{BB}$. Figure 1 is illustrating the general representation of two state Markov model. In Figure 1, the up state and down states are representing the working state and failure states of the component respectively ${ }^{10}$.

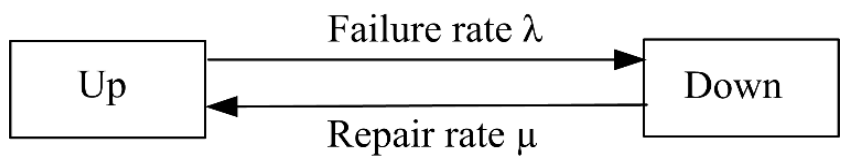

Figure 1. State space diagram of component.

Failure and repair times of all DS and substation equipment are random and it follows and exponential distribution with their respective failure rate/repair rate. The concept of exponential distribution function is explained.

An exponential distribution of a random variable $X$ has a parameter $\boldsymbol{\lambda}$ is given by.

$$
f(x)= \begin{cases}\lambda e^{-\lambda x} & \text { for } x \geq 0 \\ 0 & \text { for } x<0\end{cases}
$$

The expected mean value of the variable that having exponential distribution is given by

$$
E(X)=\frac{1}{\lambda}
$$

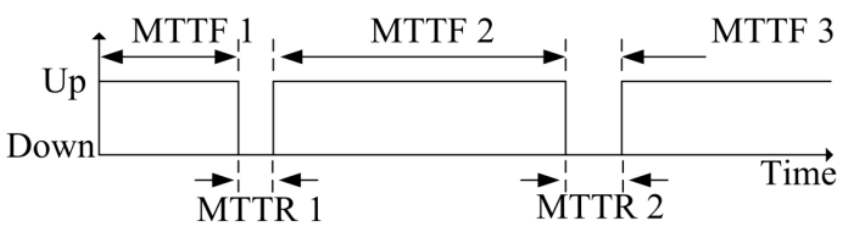

Figure 2. Element operating and repair history.

The operating and failure times of a component is represented in a two state Markov as operating and restoration history and it is shown in Figure 2. The operating and restoration times are also called by TTF/Failure Time (FT) and Time To Repair (TTR)/Repair Time (RT) respectively. The value of TTF and TTR of a component are a random and follows the exponential distribution. The mean values of TTF and TTR is calculated by equation (3). The simulated Meantime To Failure (MTTF) and Mean Time To Repair (MTTR) shown in Figure 2. The transition rate between the two states depends on the failure and repair rates respectively. 
The faulted sections are isolated from the healthy DS by using fuses and sectionalizing switches. NO switches are used to supply the power from alternative feeders after the fault isolation. The switching devices are operated in both success and failure states when its functioning is required. The operational failures of these devices are characterised as probability of success and failure. The concept of expectation is used to determine the average outage time of switching devices due to operational failures $^{8}$. The total outage time is as follows.

Outage time $=($ outage time $\mid$ success $) \times P$ (success $)+$ (outage time | failure) x P (failure)

Where

$\mathrm{P}$ (success) $=$ probability of success

$\mathrm{P}($ failure $)=$ probability of failure

\subsection{Distributed Generation Modelling}

\subsubsection{Wind Power Output Model}

The wind output power depends on the availability of the wind speed. Wind speed is intermittent by nature and depends on site, terrain and height of hub. Wind speed is the essential data required to estimate the wind output power. Due to intermittent nature, wind speed is considered as a random variable and the variable is modelled using probabilistic modelling. The Weibull distribution is the satisfactory representation of wind speed uncertainty ${ }^{23}$. The two parameter Weibull distribution function for wind speed $V_{t}$ is as follows.

$$
f\left(v_{t}\right)=\frac{k}{c}\left(\frac{v_{t}}{c}\right)^{k-1} e^{-\left(v_{t} / c\right)^{k}} \quad \text { for } \quad v_{t} \geq 0
$$

where,

$f\left(v_{t}\right)=$ Probability density function

$k$ and $c$ are the shape and scaling parameters respectively.

The estimation of Weibull shape and scale parameters of a particular site requires history of wind speed data of that site. The accuracy of parameters depends on the available data. Wind speeds have been collected from NIT Silchar and Weibull parameters are estimated using the collected data. The probability density of wind speed is shown in Figure 3. The estimated shape and scale parameter values are 2.99 and 3.78 respectively.

The Weibull parameters are used to determine the expected mean value of the random parameter i.e. wind speed.

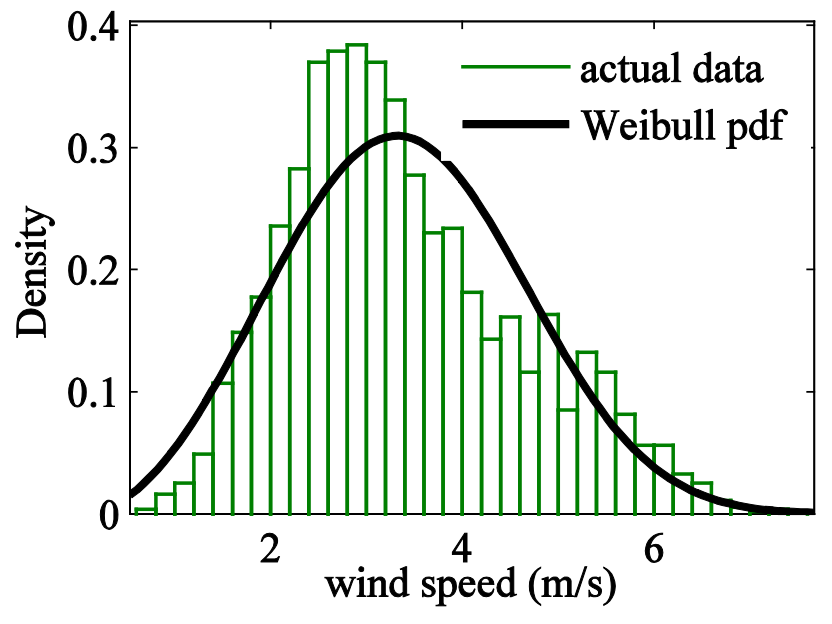

Figure 3. Probability density of wind speed.

The expected mean value $E\left(V_{t}\right)$ of the wind speed from the Weibull distribution function is calculated by using following equation (4).

$$
E\left(\mathrm{~V}_{t}\right)=c \times \Gamma(1+1 / k)
$$

The whole day wind speed is generated on hourly basis by using the expected mean value by generating random number for each hour. The wind output power is calculated by using this randomly generated hourly wind speed.

The variation of output power with wind velocity is follows the equation (6).

$$
W T_{\text {out }}=\left\{\begin{array}{ccc}
0 & \text { for } & 0 \leq V_{t}<V_{c i} \\
\left(a+b \cdot V_{t}+c \cdot V_{t}^{2}\right) P_{r} & \text { for } & V_{c i} \leq V_{t} \leq V_{r} \\
P_{r} & \text { for } & V_{r}<V_{t} \leq V_{c o} \\
0 & \text { for } & V_{t}>V_{c o}
\end{array}\right.
$$

where,

$W T_{\text {out }}$ and $P_{r}$ are the wind turbine output and turbine rated output respectively. $V_{t}, V_{c i}, V_{r}$, and $V_{c o}$ are the actual wind.

\subsubsection{Solar Output Power Model}

Solar output power depends on the solar irradiance. Solar irradiance is not constant with time. Solar output power data has been collected from NIT Silchar solar system. The probabilistic nature of hourly solar output is modelled by using the Beta distribution function reported ${ }^{7}$. The probability distribution of solar output power can be determined as follows ${ }^{5}$ : 


$$
f\left(P V_{\text {out }}\right)=\left\{\begin{array}{cl}
\frac{\Gamma(\alpha+\beta)}{\Gamma(\alpha) \Gamma(\beta)} P V_{\text {out }}^{(\alpha-1)}\left(1-P V_{\text {out }}\right)^{(\beta-1)}, & 0 \leq P V_{\text {out }} \leq 1, \alpha, \beta \geq 0 \\
0, & \text { otherwise }
\end{array}\right.
$$

where,

$f\left(P V_{\text {ou }}\right)$ is probability density function of solar output power $\alpha$ and $\beta$ are first and second shape parameters of Beta distribution. $P V_{\text {out }}$ is solar system output power.

The parameters are determined using MATLAB curve fitting tool. Probability density of solar output power is shown in Figure 4. First and second shape parameters of Beta distribution are 0.63 and 3.5 respectively.

The mean value of the solar output power is calculated using the parameters. The expected mean value of the solar output power from the Beta distribution function is calculated as follows.

$$
E\left(P V_{\text {out }}\right)=\frac{\alpha}{\alpha+\beta}
$$

The solar output power for day light hours is determined by using the expected mean value by generating random number for each hour. The day light hours are different for different locations; day light available hours are selected carefully from the available data. The day light availability hours are different for different seasons. Day light hours for this location are varies from 8 hours to 11 hours.

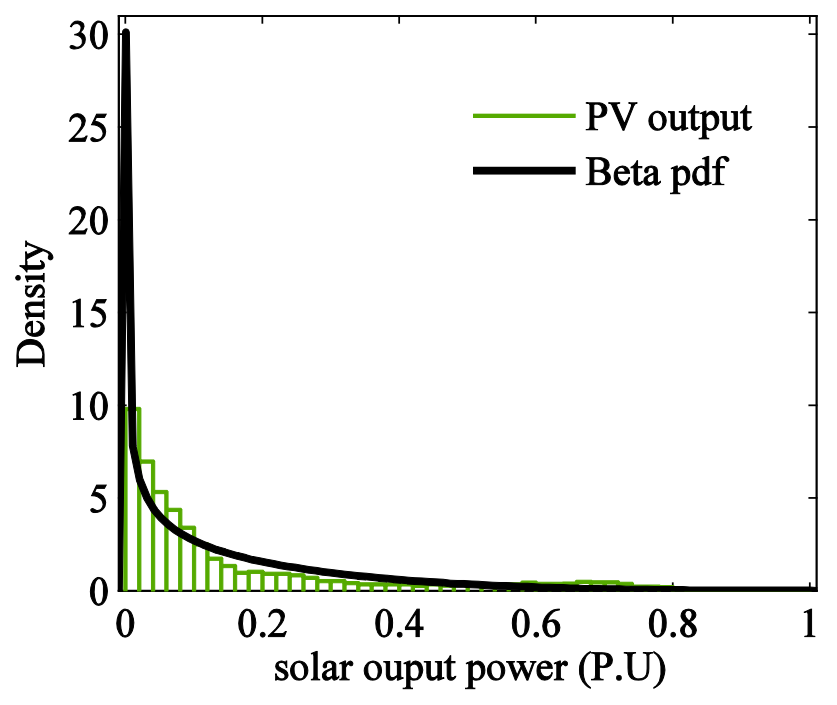

Figure 4. Probability density of solar output power.

\subsection{Load Model}

The load factor of DS depends on the different factors like weather condition, season (winter, summer and rainy) etc. The impact of these factors on DS loading is periodic in nature. Therefore, the time varying loads are determined by historical loading data. The instantaneous loading of any LP is calculated by using monthly load factor and hourly load factor as follows.

$$
P_{L_{j}}(t)=W_{h}(h) \times W_{m}(m) \times P_{m}\left(L_{j}\right)
$$

where,

$W_{h}(h)=$ Hourly load factor

$W_{m}(m)=$ Monthly load factor

$P_{m}\left(L P_{j}\right)=$ Maximum load of $L P_{j}$

$j=\mathrm{LP}$ index

\subsection{Load and DG Output Correlation}

System loading and DG outputs are time dependent, i.e. both will vary according to time. The correlation between feeder loading and DG output powers is very important for determination of available transfer able load of any feeder during failures in interconnected feeder. The load transfer capacity of a healthy feeder depends on present feeder loading and DG output power presents in that feeder. Load transfer capacity of a feeder at time tis determined as follows.

$$
\begin{aligned}
& P_{F_{i_{-}} D G}(t)=P_{F_{i}}(t)-P_{D G_{-} \text {out }}(t) \\
& T_{F_{i}}(t)=P_{\text {cap_ } F_{i}}(t)-P_{F_{i_{-} D G}}(t)
\end{aligned}
$$

where, $P_{F_{i}}(t)$ is $i^{\text {th }}$ feeder loading without DG. $P_{D G_{-} \text {out }}(t)$ is DG output power connected to $i^{\text {th }}$ feeder. $P_{F_{i_{-}} D G}(t)$ is $i^{\text {th }}$ feeder loading with DG. $T_{F_{i}}(t)$ is load transfer capacity of $i^{\text {th }}$ feeder. $P_{\text {cap_ }} F_{i}(t)$ is maximum loading capacity of $i^{\text {th }}$ feeder.

\subsection{Reliability Indices}

LP reliability is measured using basic LP reliability indices such as failure rate, average outage time, average annual outage time and energy not supplied. The calculation of basic LP reliability indices of any LP as follows ${ }^{8}$.

$$
\lambda_{L_{j}}=\sum_{i}^{N C} \lambda_{L P_{j} C_{i}}
$$

$\lambda_{L P_{j} C_{i}}=$ Failure rate of $L P_{j}$ because of component $C_{i}$ failure. 
$N C=$ Total number of components

$i=$ Component index

$U_{L P_{j}}=\sum_{i}^{N C} \lambda_{L P_{j} C_{i}} T_{L P_{j} C_{i}}$

$T_{L P_{j} C_{i}}=$ Outage time of load point $L P_{j}$ due to component $C_{i}$ failure.

$$
\begin{aligned}
& r_{L P_{j}}=U_{L P_{j}} / \lambda_{L P_{j}} \\
& E N S_{L P_{j}}=\sum_{i}^{N C} P_{L P_{j}}(t) \times T_{L P_{j}, C_{i}}
\end{aligned}
$$

$P_{L P_{j}}(t)=$ Instantaneous loading of $L P_{j}$

SAIFI, SAIDI, CAIDI and EENS are most familiar indices to measure the System and customer reliability indices. These indices are determined by using following equations.

$$
S A I F I=\sum_{j}^{N L} \lambda_{L P_{j}} N_{L P_{j}} / \sum_{j}^{N L} N_{L P_{j}}
$$

Here

$N L=$ Number of LPs

$$
\begin{aligned}
& N_{L P_{j}}=\text { Number of customers at } L P_{j} \\
& S A I D I=\sum_{j}^{N L} U_{L P_{j}} N_{L P_{j}} / \sum_{j}^{N L} N_{L P_{j}} \\
& C A I D I=\sum_{j}^{N L} U_{L P_{j}} N_{L P_{j}} / \sum_{j}^{N L} \lambda_{L P_{j}} N_{L P_{j}} \\
& E E N S=\sum_{j}^{N L} E N S_{L P_{j}}
\end{aligned}
$$

\section{Test Systems}

A practical Indian urban distribution system is used as a test system as shown in Figure 5. It is a weekly meshed and radial operated DS. Feeder loading and component fault data are collected from a practical system of Assam Power distribution corporation Limited, Assam, India. The hourly and monthly weight factors are calculated from these data for time varying load models. Component reliability data is given in Table 1 . The distribution substation having three power transformers rated 10MVA, 10MVA and 5MVA respectively as shown in Figure 6. The layout of substation and bus bars and feeder connections are as shown in Figure 6. Maximum load of the substation is $18 \mathrm{MW}$.It has three medium voltage bus bars which are connected through normally open switches to transfer loads when required. Figure 5 illustrates the geographical configuration of feeders and LPs of the system. This DS is serving total 6440 customers including domestic, commercial and large customers through 8 feeders and 295 LPs. The basic feeder data is given in Table 2. Feeders are divided into 59 sections through sectionalizing switches. The DS is modified to include PV units, wind turbine and gas turbine to different feeders.

Table 1. Component failure rate and repair time

\begin{tabular}{|l|l|l|l|}
\hline $\begin{array}{l}\text { Component } \\
\text { Type }\end{array}$ & $\begin{array}{l}\text { Failures rate } \\
\text { (failures/ } \\
\text { year) }\end{array}$ & $\begin{array}{l}\text { Repair } \\
\text { time(r) } \\
\text { (hour) }\end{array}$ & $\begin{array}{l}\text { Replacement } \\
\text { time }\left(\mathbf{r}_{\mathbf{p}}\right) \\
\text { (hour) }\end{array}$ \\
\hline $\begin{array}{l}\text { Distribution } \\
\text { transformer }\end{array}$ & 0.0843 & 200 & 10 \\
\hline $\begin{array}{l}\text { Power } \\
\text { transformer }\end{array}$ & 0.0843 & $*$ & 15 \\
\hline Lines & 0.1749 & 5 & $\star$ \\
\hline $\begin{array}{l}\text { Circuit } \\
\text { breaker }\end{array}$ & 0.004 & 4 & $\star$ \\
\hline LV bus bar & 0.001 & 2 & $\star$ \\
\hline
\end{tabular}

Table 2. Basic feeder's data

\begin{tabular}{|l|l|l|l|}
\hline $\begin{array}{l}\text { Feeder } \\
\text { Number }\end{array}$ & Length $(\mathrm{km})$ & $\begin{array}{l}\text { Load } \\
\text { points }\end{array}$ & Peak Load(MW) \\
\hline 1 & 1.5 & $1-4$ & 0.1798 \\
\hline 2 & 2.5 & $5-7$ & 0.9038 \\
\hline 3 & 11 & $8-57$ & 3.0178 \\
\hline 4 & 7 & $58-106$ & 2.9324 \\
\hline 5 & 10 & $107-150$ & 2.9721 \\
\hline 6 & 3 & $151-155$ & 0.2591 \\
\hline 7 & 6 & $156-217$ & 3.5055 \\
\hline 8 & 8 & $218-295$ & 3.6884 \\
\hline
\end{tabular}

All 8 feeders are interconnected by normally opened switches (named as SW-1 to SW-6) as shown in Figure 5. SW-1 helps to transfer the load between feeder 1 and 7 , between feeder 7 and 4 by SW-2, between feeder 2 and 8 by SW-3, between feeder 3 and 6 by SW-4, between feeder 4 and 5 by SW- 5 , between feeder 5 and 8 by SW- 6 respectively. In Figure 5, two individual PV generation units with a capacity of $1 \mathrm{MW}$ and $1.5 \mathrm{MW}$ are integrated in addition to these one2.5MWwind turbine and one $2 \mathrm{MW}$ gas turbine are connected to the DS.

It is assumed that the DG protection scheme is $100 \%$ reliable and protects DG during the fault by disconnect- 
ing from the DS. The DGs must be synchronized with the DS after the fault isolation and during the restoration process for supporting the loads of the healthy system. The start-up times of grid-tie inverters of PV and wind turbine are very less. The start-up time is neglected for the restoration process in reliability analysis. The failure rates of DGs are 0.1, 0.25 and 0.25 interruptions/year for PV units, wind turbine and gas turbine respectively. The PV, wind and gas turbines are having the average repair time of 30,20 and 8 hours respectively.

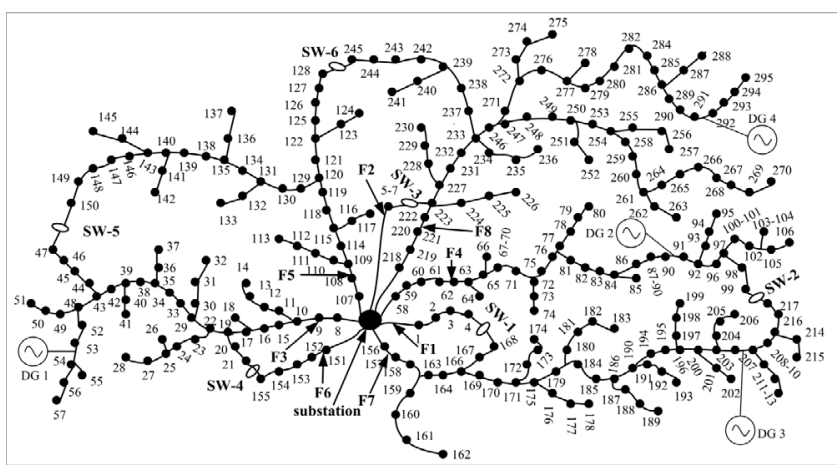

Figure 5. Single line diagram of test distribution system.

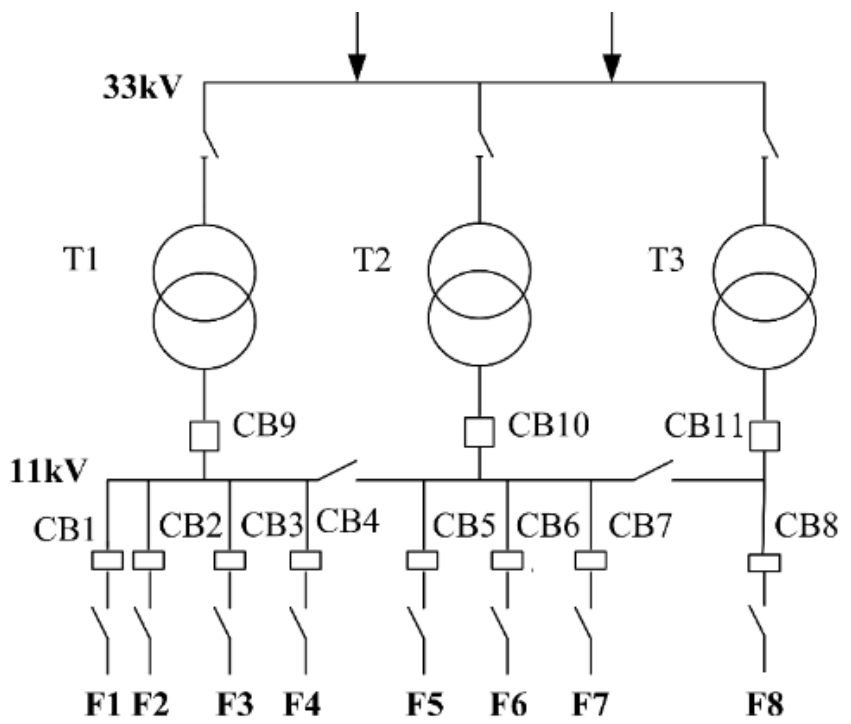

Figure 6. Single line diagram of test distribution substation.

As some data gaps are shown in Table 1, the repair of the power transformers is done by the manufactures and it is a time consuming process, so the system operators maintain spare transformers for the continued power supply. Most of the times the repairs of lines, CBs and BBs are done on site, so the replacement of these equipment is not required.

\section{Proposed Algorithm}

The proposed algorithm evaluates the reliability of the DS including substation by using time sequential MCS and time varying load patterns. The time varying load patterns will represent the actual loading of the system in a year. It is assumed that, failure/repair time of all equipment follows an exponential distribution according to their respective rates. The uncertainties of wind speed and solar irradiance for power generation is calculated by using the Weibull distribution function and Beta distribution functions respectively.

During the fault, the affected sections of the DS are determined by using a technique of the parent - visit method ${ }^{16}$. In this method, dynamic tree data structure is used to represent the DS. Branches and nodes are tied with each other through parent/offspring relationship. The affected area of fault can be identified by assigning the CBs i.e. that are used to clear the fault. The parent visit procedure is explained using the DS as shown in Figure 5. For simplicity of explanation the DS in Figure 5 is assumed as a tree representation of the DS. When a failure occurs between node 171 and 172, it examines the type of the branch between node 171 and 172. The parent node of 171 is searched i.e. node 170, then type of branch between 170 and 171 is checked. The procedure will continue until it finds the CB7 (it shown in Figure 6). The affected area covers feeder sections protected by CB7. The breath first search ${ }^{16}$ is applied for the division of LPs into different groups i.e. affected, upstream and downstream LPs. The upstream LPs are restored using main supply, possible downstream LPs are restored by using available DGs or alternate supply and affected LPs are restored after the repair of failed equipment. In this proposed algorithm the load transfer capacity of the NO switches is calculated based on the instantaneous loading of the system. The amount of restoration of load depends on the available transfer capacity/available capacity of the substation.

The flow chart of proposed algorithm is shown in Figure 7.

The proposed algorithm considers the following assumptions for reliability evaluation

i. Repair crew is available for 24 hours.

ii. Spare distribution and substation transformers available to replace faulted transformers.

iii. DG units are working online. 


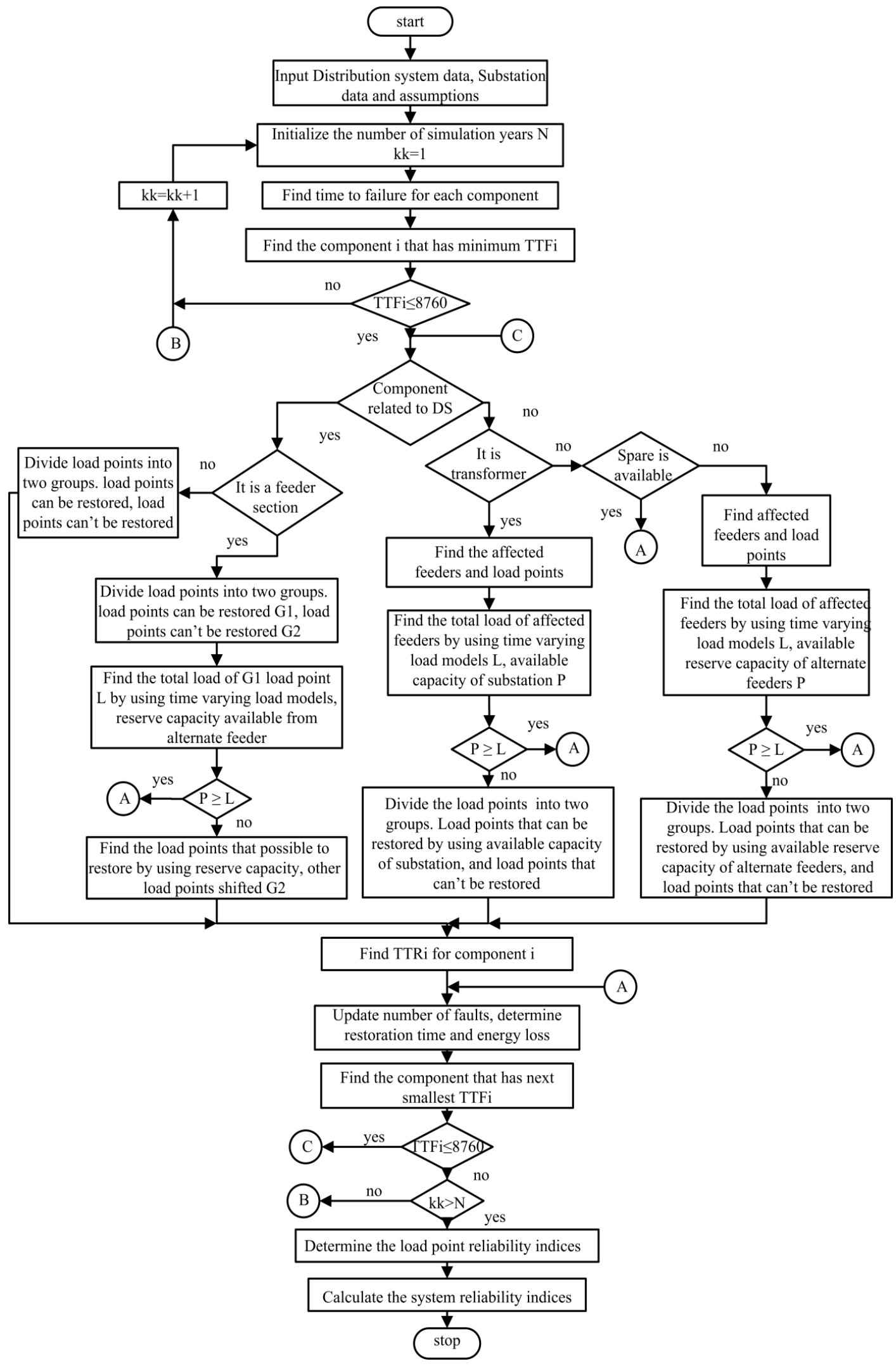

Figure 7. Flow chart for proposed reliability evaluation algorithm. 
iv. Self-load curtailment schemes applied after fault isolation and restoration of the system.

v. Lateral lines are protected by fuses.

vi. Faults are mutually exclusive events.

vii.DG faults will not effect on system normal operation. viii.Supply to the substation is $100 \%$ reliable.

\section{Results and Discussions}

Four different case studies are carried out on the test DS to analyse the effect of DS and substation automation and integration of DGs on DS reliability. The impact of operational failures of fuses, sectionalizing switches and NO switches on reliability are analysed for case 1 .

\section{Case 1: Manual Operation}

In this operation both substation and DS are manually operated. All fault management activities done manually after getting the outage related information from customers. All switches in this case are operated by the repair crew. After getting the outage information from the customers, repair crews inspect the faulted area and isolate the faulted section manually. Isolation of the faulted section will take more time to restore the unaffected LPs. Restoration time due to substation equipment faults is somewhat less compared to feeder faults. In this case isolation of fault section and switching of alternate supply are considered for $1 \mathrm{hr}$.

\section{Case 2: Manual Operation with DG}

In this case, substation and DS are manually operated. However, the presence of DGs on the feeders is considered.

\section{Case 3: Automated Operation}

In this case, both substation and feeders are completely automated. The automation system itself detects the fault

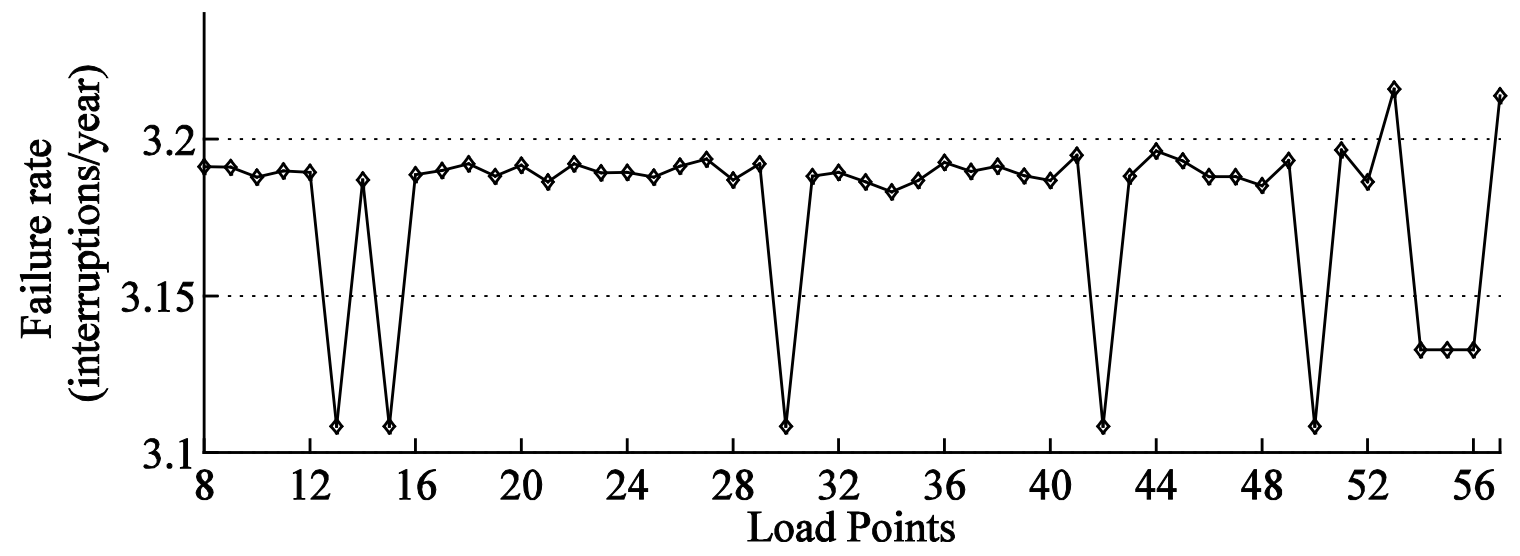

Figure 8. Failure rate indices per load points-feeder 3.

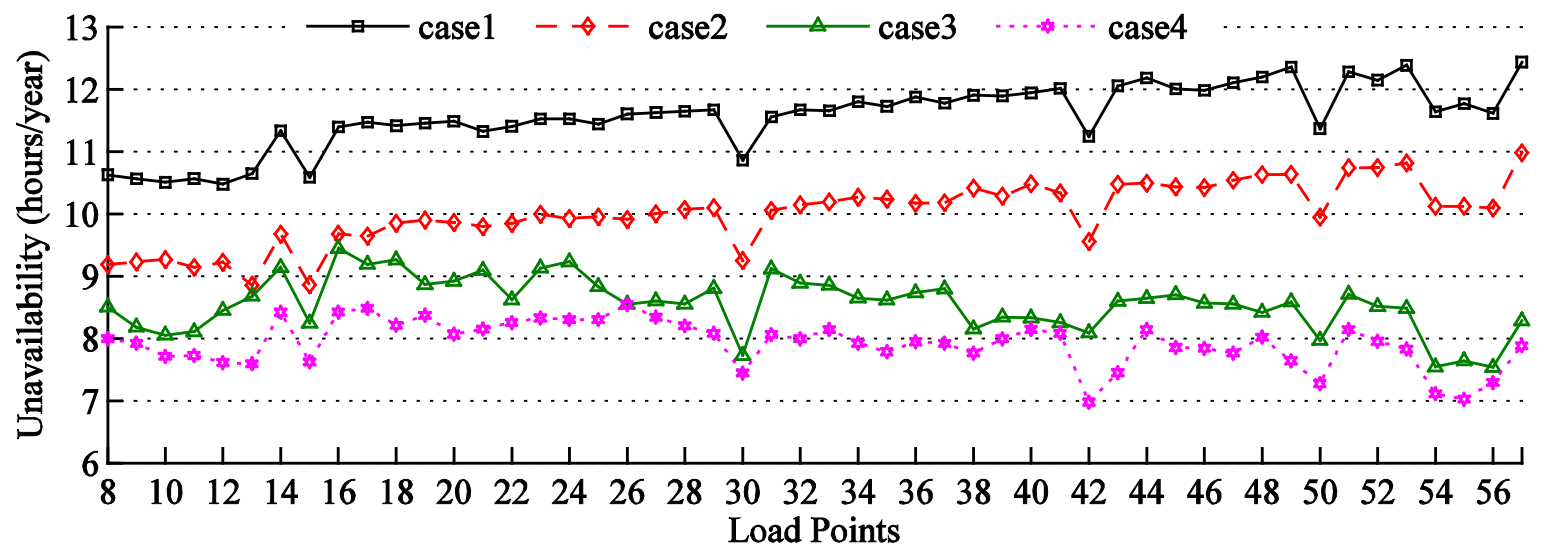

Figure 9. Unavailability indices per load points-Feeder 3. 


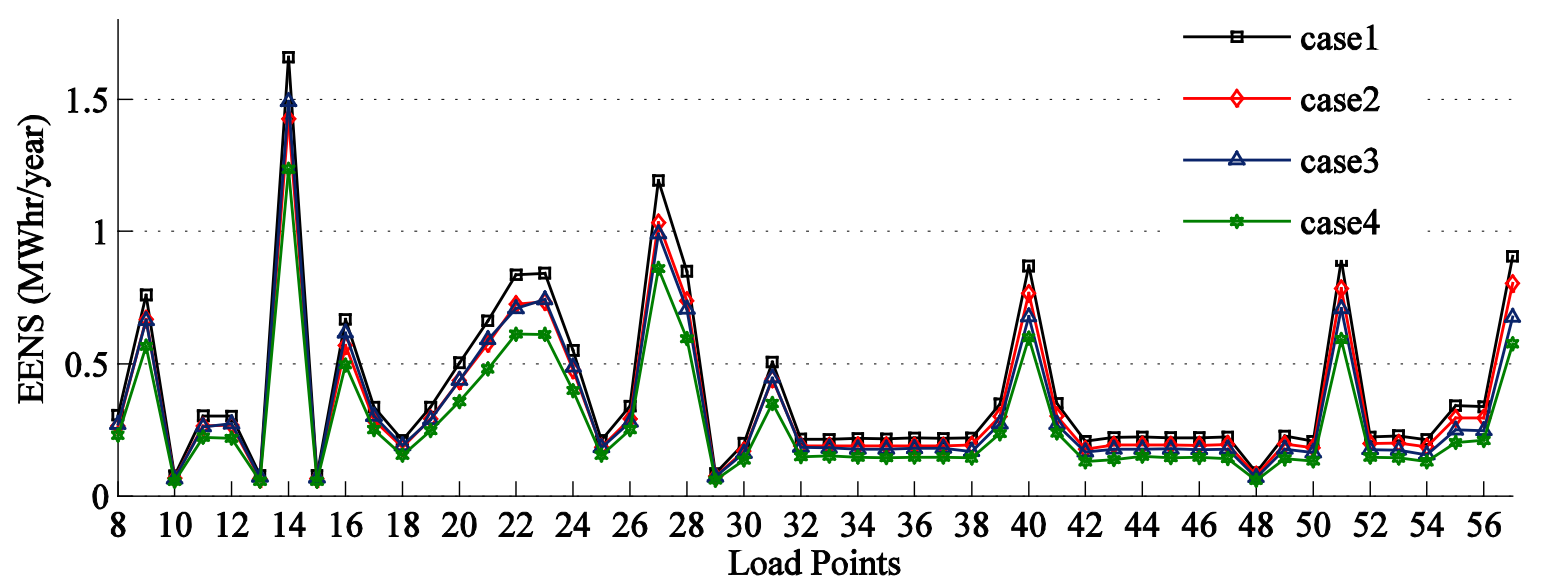

Figure 10. EENS indices per load points-Feeder 3.

location and isolates the faulted section before dispatching the repair crew. The outage time for in healthy sections are drastically reduced from hours to minutes.

\section{Case 4: Automated Operation with DG}

In this case, the DGs are integrated into the DS, feeders and substations are automated.

The results are analysed only for one feeder among the 8 feeders. The feeder 3 is arbitrarily selected as the test feeder to discuss the results. Figure 8 is showing the failure rate indices for all LPs in feeder 3. It is expected that the failure rate for all four cases is same because DG integration and automation cannot reduce the failures of the system. As shown in Figure 8 the failure rate of all LPs is almost same. The failure rate indices in Figure 8 are showing that LP13, LP15, LP30, LP42 LP50, LP54, LP55, LP56 and LP57 are less in compared to other LPs. It is expected because of these LPs are having large consumers (i.e. $11 \mathrm{kV}$ consumers) and there is no distribution transformer for these LPs. Due to this reason, the above said LPs are having less failure rate. Figure 9 is showing the unavailability indices of all LPs in feeder 3 . The unavailability of all loads on each feeder is same. The LPs having a minimum failure rate having the less unavailability. From the Figure 9, the DG integration in case 2 increase the available capacity during the fault thus reduces the restoration time of the unaffected LPs so the unavailability also reduces.

It is observed that in case 3, the outage time for unaffected LPs is greatly reduced because of introduction of automation reduces the fault detection and isolation times. It leads to quick restoration of unaffected LPs. In case 4, both automation and DGs are used to further improvement of reliability. As shown in Figure 9 unavailability of all LPs are reduced in case 4 compared to other cases. The interesting fact of the comparison is that unavailability indices of all LPs are improved proportionally in all cases. Figure10 is illustrating the EENS of all LPs of feeder 3. The results are showing that The EENS value is reduced with the application of automation and DG integration. The results witness that, the DG integration with automated DS is making the better reliability.

Table 3. System reliability indices

\begin{tabular}{|l|l|l|l|l|}
\hline & Case 1 & Case 2 & Case 3 & Case 4 \\
\hline SAIFI & 2.7580 & 2.7580 & 2.7580 & 2.7580 \\
\hline SAIDI & 10.7799 & 9.3355 & 8.1286 & 7.7006 \\
\hline CAIDI & 3.9284 & 3.4139 & 2.9472 & 2.8102 \\
\hline EENS & 105.0104 & 90.6583 & 89.6183 & 74.9561 \\
\hline
\end{tabular}

Table 4. Relative changes of system reliability indices

\begin{tabular}{|l|l|l|l|}
\hline & Case 2 \& 1 & Case 3 \& 1 & Case 4 \& 1 \\
\hline SAIDI & -13.399 & -24.5948 & -28.5652 \\
\hline CAIDI & -13.0969 & -24.977 & -28.4645 \\
\hline EENS & -13.6673 & -14.6576 & -28.6203 \\
\hline
\end{tabular}

The system reliability indices are presented in Table 3. It is observed that SAIFI is unchanged while the other reliability indices are improving in all four cases. It is expected because SAIFI will depend on the load point failure rate. Integration of DG in the system in both manual and automation cases, the SAIDI, CAIDI and EENS are greatly improved. It is observed that from case 2 and case 3 there is no significant improvement in EENS, while 
SAIDI and CAIDI are improved. In case 4, SAIDI, CAID and EENS are greatly improved compared to case 1 due to automation and DG integration. The relative changes of SAIDI, CAIDI and EENS with respect to case 1 are presented in Table 4 . It is observed that change of EENS is almost same for case 2 and case 3 .

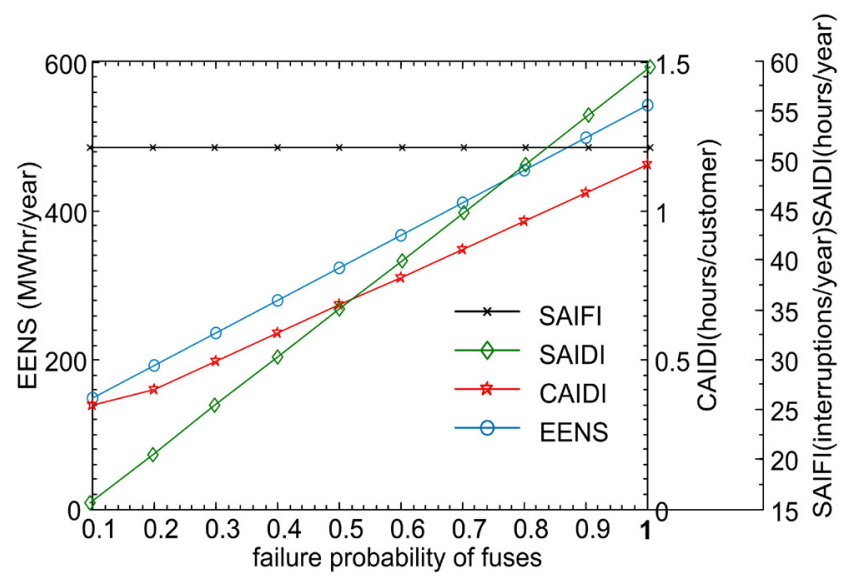

Figure 11. Impact of fuse failures on reliability.

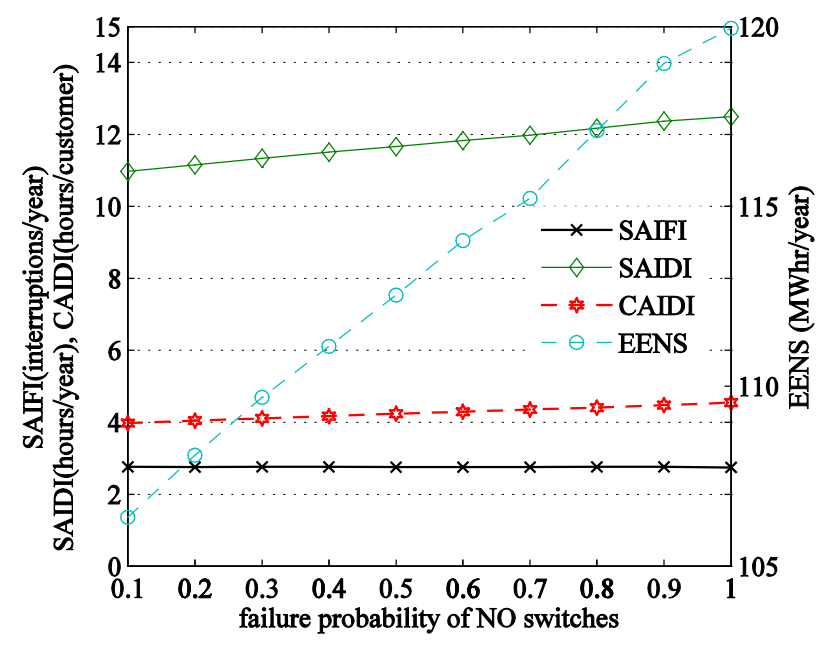

Figure 12. Impact of NO switch failures on reliability.

Figure 11 shows the impact of fuse failures on system reliability. SAIFI is greatly increased as compared to zero fuse failure case and it remains constant with increasing the failure probability. Due to the high value of SAIFI, the CAIDI is less. SAIDI and CAIDI are increasing with increasing of probability of failure. EENS is drastically increasing with increase of failure probability. Figure 12 and Figure 13 shows impact of NO switch failures (failure of load transferring) and sectionalizing switch failures on system reliability respectively. It is observed that there is no change in SAIFI in both cases. SAIDI, CAIDI and EENS are increasing with increase of failure probability. NO and sectionalizing switches are operated after de energising the faulted feeder. These operational failures will not effect on healthy sections and no change in system failures. On other hand, these operational failures increase the isolation and restoration times. Due to this reason SAIDI, CAIDI and EENS values are changing with probability of failure.

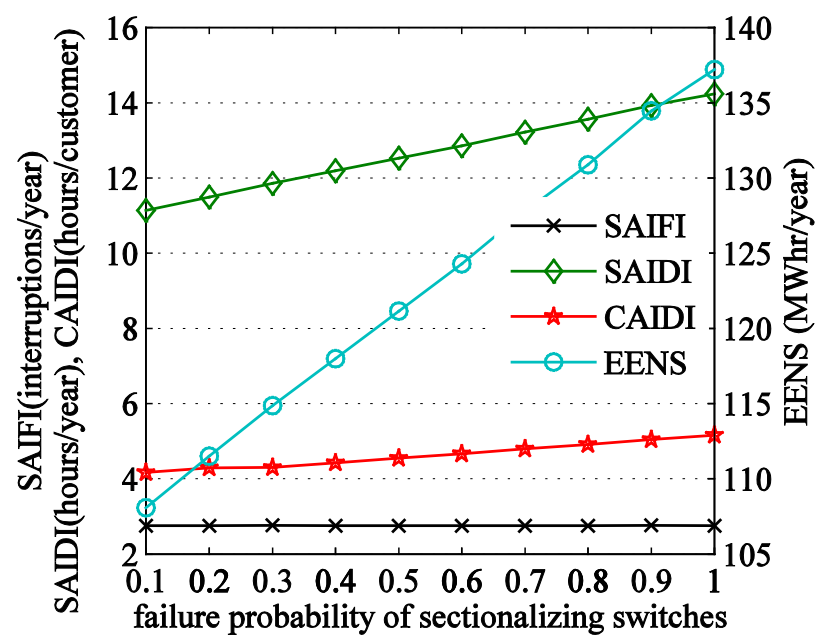

Figure 13. Impact of sectionalizing switch failures on reliability.

\section{Conclusion}

This paper mainly aimed to compare the effects of the automation, DG integration to the distribution system considering operational failure of fuses and switches. These works described a methodology based on time sequential MCS with time varying loads to evaluate the reliability indices. Stochastic modelling is used for component modelling and the uncertainties of wind and solar output powers are modelled by using probability distribution functions. The evaluation of the reliability of the system by considering all the equipment in both feeders and substation and failures of DGs. System oriented indices SAIDI, CAIDI and EENS are improved while using automation and DG integration. It is observed that there is no change of SAIFI. There is no significant relative change in EENS between automation case and DG integration case, while other indices are improved with automation. The operational failures of fuses and switches are reducing the reliability. Fuse failures greatly increases 
the SAIFI, SAIDI and EENS. Switch failures not showing any impact on SAIFI while other indices are increased. In future energy storage units with DGs, system load growth, priority based load restoration, and different load patterns for different types of customers are considered in reliability evaluation.

\section{References}

1. Wang P, Billinton R. Time sequential distribution system reliability worth analysis considering time varying load and cost models. IEEE Transactions on Power Delivery. 1999 Jul; 14(3):1046-52. https://doi.org/10.1109/61.772352

2. Zhu D, Broadwater RP, Tam KS, Seguin R, Asgeirsson H. Impact of DG placement on reliability and efficiency with time-varying loads. IEEE Transactions on Power Systems. 2006 Feb; 121(1):419-27. https://doi.org/10.1109/ TPWRS.2005.860943

3. Murty VVSN, Kumar A. Mesh distribution system analysis in presence of distributed generation with time varying load model. International Journal of Electrical Power Energy Systems. 2014 Nov; 62:836-54. https://doi.org/10.1016/j. ijepes.2014.05.034

4. Ochoa LF, Padilha-Feltrin A, Harrison GP. Evaluating distributed time-varying generation through a multiobjective index. IEEE Transactions on Power Delivery. 2008 Apr; 23(2):1132-8. https://doi.org/10.1109/ TPWRD.2008.915791

5. Miao F, Vittal V, Heydt GT, Ayyanar R. Probabilistic power flow studies for transmission systems with photovoltaic generation using cumulants. IEEE Transactions on Power Systems. 2012 Nov; 27(3):2251-61.

6. Hung DQ, Mithulananthan N, Lee KY. Determining PV penetration for distribution systems with time-varying load models. IEEE Transactions on Power Systems. 2014 Nov, 29(6):3048-57. https://doi.org/10.1109/ TPWRS.2014.2314133

7. Salameh ZM, Borowy BS, Amin ARA. Photovoltaic module-site matching based on the capacity factors. IEEE Transactions on Energy Conversion. 1995 Jun; 10(2):32632. https://doi.org/10.1109/60.391899

8. Billinton R, Alan RN. Reliability evaluation of power systems, 2nd Edition. Plenum Press: New York; 1995.

9. Billinton R, Li W. Reliability assessment of electric power systems using monte carlo methods, 1st Edition. Springer; 1994. https://doi.org/10.1007/978-1-4899-1346-3

10. Billinton R, Wang P. Teaching distribution system reliability evaluation using Monte Carlo simulation. IEEE Transactions on Power Systems. 1999 May; 14(2):397-403. https://doi.org/10.1109/59.761856
11. Billinton R, Lian G. Monte Carlo approach to substation reliability evaluation. IEE Proceedings C - Generation, Transmission and Distribution. 1993 Mar; 140(2):147-52.

12. Veliz FFC, Borges CLT, Rei AM. comparison of load models for composite reliability evaluation by non sequential Monte Carlo Simulation. IEEE Transactions on Power Systems. 2010 May; 25(2):649-56. https://doi.org/10.1109/ TPWRS.2009.2032354

13. Moazzami M, Hemmati R, Fesharaki FH, Rad SR. Reliability evaluation for different power plant busbar layouts by using sequential Monte Carlo simulation. International Journal of Electrical Power Energy Systems. 2013 Dec; 53:987-93. https://doi.org/10.1016/j.ijepes.2013.06.019

14. Bie Z, Zhang P, Li g, Hua B, Meehan M, Wang X. Reliability evaluation of active distribution systems including microgrids. IEEE Transactions on Power Systems. 2012 Nov; 27(4):2342-50. https://doi.org/10.1109/ TPWRS.2012.2202695

15. Billinton R, Cui L, Pan Z, Wang P. Probability distribution development in distribution system reliability evaluation. Electric Power Components Systems. 2010 Nov; 30(9):90716. https://doi.org/10.1080/15325000290085217

16. Li W, Wang P, Li Z, Liu Y. Reliability evaluation of complex radial distribution systems considering restoration sequence and network constraints. IEEE Transactions on Power Delivery. 2004 Apr; 19(2):753-8. https://doi. org/10.1109/TPWRD.2003.822960

17. Wang P, Li W. Reliability evaluation of distribution systems considering optimal restoration sequence and variable restoration times. IET Generation Transmission Distribution. 2007 Jul; 1(4):688-95. https://doi.org/10.1049/ietgtd:20060451

18. Che L, Zhang X, Shahidehpour M, Alabdulwahab A, Abusorrah A. Optimal interconnection planning of community micro grids with renewable energy sources. IEEE Transactions on Smart Grid. 2017 May; 8(3):1054-63. https://doi.org/10.1109/TSG.2015.2456834

19. Leite da Silva AM, Nascimento LC, da Rosa MA, Issicaba D, Peças Lopes JA. Distributed energy resources impact on distribution system reliability under load transfer restrictions. IEEE Transactions on Smart Grid. 2012 Dec; 3(4):2048-55. https://doi.org/10.1109/TSG.2012.2190997

20. G. H. Reddy, A.k. Goswami, Nalin B Dev Choudhury, Impact of Plug-in Electric Vehicles and Distributed Generation on Reliability of Distribution Systems. Engineering Science and Technology, an International Journal. 2018 February; 21(1):50-59.

21. Khalesi N, Javadian SAM. Distribution system reliability with considering variation in DG and load consumption. Indian Journal of Science and Technology. 2011 Oct; 4(10):1285-1289. 
22. Cheng D, Onen A, Zhu D, Kleppinger D, Arghandeh R, Broadwater RP, Scirbona C. Automation effects on reliability and operation costs in storm restoration. Electric Power Components Systems. 2015 Mar; 43(6):656-64. https://doi. org/10.1080/15325008.2014.999146
23. Sanij MD, Dehghani-Ashkezari M, Hashemi-Dezaki H. Optimum reserve estimation in micro-grids containing renewable distributed generation resources. Indian Journal of Science and Technology. 2015 Oct; 8(28):1-9. 